\title{
ELABORAÇÃO DE DIRETRIZ CLÍNICA: INTEGRAÇÃO ENTRE UNIVERSIDADE E UNIDADE HOSPITALAR*
}

Derdried Athanasio Johann ${ }^{1}$, Priscila Mingorance ${ }^{2}$, Luciana Souza Marques De Lazzari ${ }^{3}$, Edivane Pedroloㄹ, Tatiana Queiroz Ribeiro de Almeida ${ }^{3}$, Mitzy Tannia Reichembach Danski ${ }^{4}$

RESUMO: Os revezes enfrentados na prática cotidiana do trabalho da enfermagem são temas para as pesquisas de graduação e pós-graduação, enquanto o profissional à beira do leito necessita atualizar-se e buscar as melhores evidências para oferecer qualidade no cuidado. Refletimos a respeito de como a academia pode integrar-se à prática e, assim, contribuir para melhoria do cuidado ao elaborar e implantar diretrizes clínicas. Os atarefados profissionais, por vezes, não têm a oportunidade de debruçar-se sobre as ferramentas de busca da literatura e selecionar as melhores evidências a serem implantadas em sua unidade. Para academia, entretanto, esse tipo de pesquisa é habitual, sendo plenamente viável a elaboração de diretrizes clínicas e sua implantação nas unidades pesquisadas. Objetivou-se refletir sobre a integração universidade e unidade hospitalar, tendo como foco a elaboração conjunta de diretriz clínica.

PALAVRAS-CHAVE: Guia de prática clínica; Educação continuada; Enfermagem; Tecnologia.

\section{ELABORATION OF CLINICAL PRACTICE GUIDELINES: INTEGRATION BETWEEN UNIVERSITY AND HOSPITAL UNIT}

ABSTRACT: The setbacks confronted in daily nursing routines are themes in undergraduate and postgraduate research, while the healthcare professional at the bedside needs to update her skills and seek the best evidence so as to offer quality care. The authors reflect on how academia can integrate itself to practice and thus contribute to improving care by elaborating and implanting clinical practice guidelines. The busy healthcare professionals sometimes do not have the opportunity to consider their literature search tools and select the best evidence to implant in their unit. For academia, however, this type of research is habitual, with the elaboration of clinical practice guidelines and their implantation in the units researched being perfectly viable. An objective was to reflect on the integration of university and hospital units, with a focus on the joint elaboration of clinical practice guidelines.

KEYWORDS: Clinical practice guidelines; Continued education; Nursing; Technology.

\section{ELABORACIÓN DE DIRETRIZ CLÍNICA: INTEGRACIÓN ENTRE UNIVERSIDAD Y UNIDAD HOSPITALAR}

RESUMEN: Las dificultades afrontadas en la práctica cotidiana del trabajo de enfermería son temas para las investigaciones de graduación y posgrado, mientras el profesional que atiende el lecho necesita atualizarse y buscar las mejores evidencias para ofrecer cualidade en el cuidado. Hemos reflexionado acerca de cómo la academia puede integrarse a la práctica y, de ese modo, contribuir para el desarrollo del cuidado al elaborar e implantar diretrizes clínicas. Los atareados profesionales, por veces, no tienen oportunidad de dedicarse a las herramientas de búsqueda de la literatura y eligir las mejores evidencias a implantar en su unidad. Para academia, sin embargo, ese tipo de investigación es habitual, siendo plenamente viable la elaboración de diretrizes clínicas y su implantación en las unidades investigadas. El objetivo de este trabajo fue reflexionar sobre la integración universidad y unidad hospitalar, a la luz de la elaboración conjunta de diretriz clínica.

PALABRAS CLAVE: Guía de práctica clínica; Educación continuada; Enfermería; Tecnología.

*Extraido da Dissertação de Mestrado Acadêmico pelo Programa de Pós-Graduação em Enfermagem da Universidade Federal do Paraná - PPGENF UFPR, intitulada Complicações relacionadas ao uso do Cateter Central de Inserção Periférica no Neonato, 2011.

${ }^{1}$ Enfermeira do Instituto Federal do Paraná. Mestre em Enfermagem. Membro do Grupo de Pesquisa Tecnologia e Inovação em Saúde: Fundamentos para Prática de Enfermagem - TIS.

${ }^{2}$ Acadêmica de Enfermagem pela UFPR. Bolsista de Iniciação Científica PIBIC/CNPQ. Membro do TIS.

${ }^{3}$ Acadêmica de Enfermagem pela UFPR. Bolsista Voluntária de Iniciação Científica. Membro do TIS

${ }^{4}$ Enfermeira. Doutora em História. Professora do Departamento de Enfermagem e do PPGENF UFPR. Vice-líder do TIS. 


\section{INTRODUÇÃO}

A vivência com a pesquisa durante a graduação e a pós-graduação possibilita identificar a realidade na qual os profissionais de saúde atuam, levantando principalmente as dificuldades encontradas ao desempenhar suas atividades.

Muitos são os empecilhos na prática hospitalar, pois a inserção contínua de novas tecnologias na área da saúde direciona a busca de aprimoramento no conhecimento dos profissionais que necessitam atualizar-se constantemente. A parceria entre universidade e unidade hospitalar pode ser significativa para atender a demanda de atualizações constantes; e os programas de iniciação científica e de pós-graduação figuram como opções que viabilizam a integração entre a academia e o serviço.

Tem-se como exemplo dessa integração a elaboração de uma "Diretriz Clínica para Cateter Central de Inserção Periférica". A universidade, representada por professores, mestrandos e alunos de iniciação científica, associou-se aos enfermeiros de uma Unidade de Terapia Intensiva Neonatal (UTINeo), com vistas a elaborar uma diretriz clínica baseada em evidências. Esta integração é de suma importância para a construção de uma diretriz, pois permite o confronto das evidências, elencadas em literatura relevante pelos membros da academia, com a realidade do serviço em questão, representada pelos enfermeiros que atuam na UTINeo. Desta forma, é possível adequar as evidências, em sua maioria internacionais, à realidade dos hospitais públicos brasileiros, a fim de torná-las viáveis na prática diária.

Esta experiência nos levou a refletir sobre a relação teoria e prática, universidade e unidade hospitalar, na construção do conhecimento em Enfermagem. Destaca-se que a formação acadêmica deve enfatizar uma formação ímpar, que permita ao aluno tornarse um profissional livre, crítico e criativo diante das questões cotidianas, com domínio das tecnologias, do trabalho em equipe e dotado de boa comunicação( ${ }^{(1)}$. Estas habilidades são desenvolvidas, em sua maioria, nas aulas práticas em ambiente hospitalar. Entretanto, percebe-se a necessidade de integrar, de forma mais efetiva, a prática hospitalar às discussões e descobertas realizadas pela academia, a fim de possibilitar a implantação dos conhecimentos gerados.

Neste contexto, a integração universidade e unidade hospitalar faz-se fundamental, uma vez que propicia benefícios para ambas as partes. Para os acadêmicos versa seu espírito questionador e cria habilidades essenciais para soluções eficazes e inovadoras frente às questões inerentes à prática. Para equipe hospitalar, permite atualização frente às novas tecnologias disponíveis, facilitando sua implementação na prática, bem como reflexão sobre seu processo de trabalho.

Frente ao exposto, tem-se como objetivo refletir sobre a integração universidade e unidade hospitalar, tendo como foco a elaboração conjunta de diretriz clínica.

\section{INTEGRAÇÃO UNIVERSIDADE E UNIDADE HOSPITALAR}

A realidade hospitalar é um ambiente propício para construir o conhecimento, pois com a disseminação e atualização a despeito de novas tecnologias, o cuidado prestado aos clientes tende a qualificar-se constantemente. Diante desse contexto, o ensino, a pesquisa e a crítica integram-se à realidade profissional do enfermeiro atuante no âmbito hospitalar, propiciando o processo de ensino aprendizagem dos profissionais que atuam diretamente no cuidado e dos participantes de projetos de pesquisa.

Uma maneira útil de integrar a universidade à prática hospitalar é a elaboração conjunta de diretrizes clínicas, de modo a atualizar o conhecimento dos profissionais a respeito de tecnologias, novas ou de controversa aplicação, tal como desenvolvido na UTINeo para inserção, manutenção e retirada de cateter central de inserção periférica.

Considerando-se a pesquisa como uma ferramenta para a consolidação da teoria na prática profissional, esta figura como peça-chave no relacionamento entre a universidade e a unidade hospitalar, facilitando o diálogo entre as instituições. É possível, portanto, desenvolver em projetos de pesquisa, guias que subsidiem a prática clínica, com o intuito de orientar a um cuidado de enfermagem atualizado e de qualidade.

Diretrizes clínicas são instrumentos úteis, capazes de estabelecer a conexão entre teoria e prática vivenciadas durante os cuidados prestados. É um documento direcionado a todos os profissionais de saúde com informações de fácil entendimento ${ }^{(2)}$; contém recomendações de tratamento e cuidado apropriado de pessoas com determinadas doenças e condições. São baseadas nas melhores evidências disponíveis e auxiliam os profissionais de saúde em sua prática profissional; podem ser utilizadas para nortear os cuidados dos indivíduos; desenvolver padrões de práticas clínicas que possam ser mensurados; treinar e educar o profissional ${ }^{(3)}$.

As características das diretrizes baseadas em evidências tornam a pesquisa instrumento essencial na busca de conhecimentos fidedignos a serem aplicados na prática profissional. A prática baseada em evidências 
é um método que utiliza evidências científicas para auxiliar a tomada de decisões na prática clínica. As evidências científica resultam de estudos com critérios metodológicos rigorosos ${ }^{(4)}$. Para tanto, contribui com a prática profissional do enfermeiro, posto que as evidências são selecionadas e específicas para embasar o cuidado, no qual a habilidade clínica do profissional, em conjunto com a preferência do paciente, são de fundamental importância.

Pesquisar e relacionar os dados encontrados à prática profissional vai além da simples aplicação desses cuidados, ressalta-se a importância do profissional enfermeiro em adequar à realidade local, bem como refletir as novas experiências e/ou vivências para com a equipe de enfermagem. Destaca-se que a pesquisa inexiste sem o ensino e vice-versa ${ }^{(3)}$, de maneira que se houve pesquisa é por que houve o ensino, a indagação, a constatação e a intervenção, o que retorna à pesquisa, formando o ciclo gnosiológico ${ }^{(5)}$. A educação, inerente à prática acadêmica, é necessária em todo processo de transformação. Assim, a integração entre pesquisa, pesquisadores e profissionais torna-se fundamental ao cotidiano e à realidade prática do cuidado.

A pesquisa cumpre seu papel no ensino, tanto corroborando práticas já instituídas, corretamente aplicadas, como aprimorando a qualidade do cuidado; também promove a transformação da realidade, pois estimula criticidade suficiente para induzir mudanças cabíveis no processo de cuidar ${ }^{(6)}$. A pesquisa, o ensino e a intervenção estão diretamente ligados à área da saúde, posto que as inovações nessa área dão-se constantemente e em proporções avassaladoras.

A integração universidade e unidade hospitalar propicia a fusão da prática, mediante incorporação de novas tecnologias ao cuidado e desenvolvimento de pensamento crítico inerente ao exercício profissional; do ensino, mediante embasamento científico do cuidado; e da pesquisa, envolvida no desenvolvimento ou aperfeiçoamento de tecnologias ou práticas do cuidar.

Evidencia-se ainda, que o conhecimento refletido coletivamente e experimentado gera responsabilidades e compromissos partilhados, levando a decisões conscientes ${ }^{(7)}$.

Destaca-se que a participação da universidade no ambiente hospitalar traz contribuições para introdução de novos procedimentos, tomada de decisão e melhoria da qualidade do cuidado, sendo base para uma política de planejamento, supervisão e avaliação com autonomia da enfermagem ${ }^{(8)}$. E a unidade hospitalar influencia a universidade por aproximá-la às novas tecnologias e, apresentar as condições de trabalho segundo a rea- lidade vivenciada no dia-a-dia.

Integrar compreende abertura ao diálogo e a discussão, bem como respeito às divergências, permitindo aos atores a construção ou reconstrução de sua prática ${ }^{(8)}$. Para tanto, necessitam desenvolver uma reflexão crítica acerca dos componentes e dos integrantes envolvidos no processo, bem como dos reais objetivos das ações desenvolvidas.

Desta forma, os profissionais atuantes no cuidado direto são sujeitos que atuam na sua realidade de forma a modificá-la com a permanente construção e reconstrução do conhecimento ${ }^{(5)}$. Assim, o conhecimento construído, perante a elaboração da diretriz clínica, permeia a mudança na realidade dos profissionais, por meio da idealização de uma ferramenta que servirá de base para futuras intervenções e para os cuidados prestados. O desenvolvimento e implantação de diretrizes clínicas são atividades de pesquisa que enriquecem a prática de enfermagem sobremaneira, promovendo a integração entre a prática de cuidar e a pesquisa em enfermagem.

\section{CONSIDERAÇÕES FINAIS}

A demanda elevada de trabalho e o número reduzido de profissionais de saúde nas unidades hospitalares minimizam as chances de atualização de conhecimentos baseados em evidências científicas por parte dos profissionais. Assim, a integração entre universidade e unidade hospitalar propicia benefícios a ambas as partes. De um lado, a universidade, por meio de seus projetos de iniciação científica, graduação e pós-graduação, pode colaborar com a realidade dos serviços de saúde, ao pesquisar buscando as melhores evidências científicas nacionais e internacionais relacionadas à prática profissional e em conjunto implementá-las de fato. De outro lado, as unidades hospitalares, apropriam-se desses conhecimentos, o que reflete em uma gestão qualificada e melhoria do cuidado prestado.

A atualização e/ou aquisição de conhecimentos transforma a prática cotidiana e a curiosidade ingênua em reflexões críticas dessa prática, propicia ao profissional situar-se como sujeito central do processo de cuidar embasado em literatura relevante, traduz o conhecimento apreendido para a sua realidade, tornando possível reduzir práticas errôneas e insegurança.

Aos pesquisadores permanece o aprendizado contínuo, aliando a produção bibliográfica, prática e experiência profissional, confrontando os limites histórico, social, cultural e científico. 


\section{REFERÊNCIAS}

1. Fornaziero CC, Gordan PA, Carvalho MAV, Araujo JC, Aquino JCB. O ensino da anatomia: integração do corpo humano e meio ambiente. Rev. bras. edu. med. 2010;34(2):290-7.

2. Springhouse I. Trad. Garcez RM. As melhores práticas de enfermagem: procedimentos baseados em evidencias. $2^{\text {a }}$ ed. Porto Alegre: Artmed; 2010.

3. National Institute for Clinical Excellence. [acesso em 18 abr 2010] Disponível: www.nice.org.uk.

4. Pedrolo E, Danski MTR, Mingorance P, DeLazzari LSM, Meier MJ, Crozeta K. A prática baseada em evidências como ferramenta para a prática profissional do enfermeiro. Cogitare enferm. 2009;14(4):760-3.

5. Freire P. Pedagogia da autonomia. Saberes necessários à prática educativa. São Paulo: Paz e Terra; 1996.

6. Paschoal AS, Mantovani MF, Meier MJ. Percepção da educação permanente, continuada e em serviço para enfermeiros de um hospital de ensino. Rev Esc Enferm USP. 2007; 41(3):478-84.

7. Leite ICN. Função social da universidade: uma experiência de integração universidade-escola com alunas do curso de pedagogia da UEFS. Sitientibus. 2004;31:169-78.

8. Olschowsky A, Silva GB. Integração docenteassistencial: um estudo de caso Rev Esc Enferm USP. 2000;34(2):128-37.

9. Costa MHA. Impacto na incidência de infecção relacionada a cateter vascular central após medidas de educação na unidade de terapia intensiva do Hospital Universitário João de Barros Barreto. [dissertação]. Belém (PA): Universidade Federal do Pará; 2007.

10. Sakita NK. Cateterismo central por inserção periférica em UTI neonatal de nível terciário: incidência de complicações e fatores de risco associados [dissertação]. São Paulo(SP): Faculdade de Medicina da Universidade de São Paulo; 2009.

11. Camargo PP. Procedimento de inserção, manutenção e remoção do cateter central de inserção periférica em neonatos [dissertação]. São Paulo(SP): Escola de Enfermagem da Universidade de São Paulo; 2007.

12. Elias MA, Navarro VL. A relação entre o trabalho, a saúde e as condições de vida: negatividade e positividade no trabalho das profissionais de enfermagem de um hospital escola. Rev. Latino-Am. Enfermagem. 2006;14(4):517-25. 